This item was submitted to Loughborough's Research Repository by the author.

Items in Figshare are protected by copyright, with all rights reserved, unless otherwise indicated.

\title{
Cold atmospheric gas plasma disinfection of chicken meat and chicken skin contaminated with Listeria innocua
}

PLEASE CITE THE PUBLISHED VERSION

http://dx.doi.org/10.1016/j.fm.2011.05.007

PUBLISHER

(C) Elsevier

VERSION

SMUR (Submitted Manuscript Under Review)

LICENCE

CC BY-NC-ND 4.0

\section{REPOSITORY RECORD}

Noriega, Estefania, Gilbert Shama, Adriana Laca, Mario Diaz, and Michael G. Kong. 2011. "Cold Atmospheric Gas Plasma Disinfection of Chicken Meat and Chicken Skin Contaminated with Listeria Innocua". figshare. https://hdl.handle.net/2134/8675. 


\section{Cold Atmospheric Gas Plasma Disinfection of Chicken Meat and Chicken Skin} contaminated with Listeria innocua

Estefanía Noriega ${ }^{1}$, Gilbert Shama ${ }^{2 *}$, Adriana Laca ${ }^{1}$, Mario Díaz ${ }^{1}$ and Michael G. Kong ${ }^{3}$

${ }^{1}$ Department of Chemical Engineering and Environmental Technology, University of Oviedo, C/ Julián Clavería, s/n, 33006 Oviedo, Spain

${ }^{2}$ Department of Chemical Engineering and ${ }^{3}$ Department of Electronic and Electrical Engineering, Loughborough University. Leicestershire LE11 3TU, UK

\section{*Corresponding author:}

Tel: +44 1509 222514; Fax: +44 1509223923

E-mail: G.Shama@Lboro.ac.uk (G. Shama) 


\section{ABSTRACT}

Gas plasmas generated at atmospheric pressure and ambient temperatures offer a possible decontamination method for poultry products. The efficacy of cold atmospheric gas plasmas for decontaminating chicken skin and muscle inoculated with Listeria innocua was examined. Optimization of operating conditions for maximal bacterial inactivation was first achieved using membrane filters on which $L$. innocua had been deposited. Higher values of AC voltage, excitation frequency and the presence of oxygen in the carrier gas resulted in the greatest inactivation efficiency, and this was confirmed with further studies on chicken muscle and skin. Under optimal conditions, a $10 \mathrm{~s}$ treatment gave $>3 \log$ reductions of $L$. innocua on membrane filters, an 8 min. treatment gave 1 log reduction on skin, and a 4 min. treatment gave $>3 \log$ reductions on muscle. These results show that the efficacy of gas plasma treatment is greatly affected by surface topography. Scanning electron microscopy (SEM) images of chicken muscle and skin revealed surface features wherein bacteria could effectively be protected from the chemical species generated within the gas plasma. The developments in gas plasma technology necessary for its commercial application to foods are discussed.

Keywords: cold atmospheric gas plasma, decontamination, chicken skin, chicken muscle, Listeria innocua,

\section{Introduction}


Poultry carcasses are commonly contaminated with enteric pathogens such as Salmonella, Campylobacter and Listeria monocytogenes (Jacobsreitsma et al., 1994; Murphy et al., 2004), the possibility of cross-contamination of poultry carcasses post slaughter is high. Decontamination of poultry carcasses is therefore desirable. Various decontamination technologies have been proposed including the use of various chemical agents such as alkali (Rodriguez De Ledesma et al., 1996), physical methods such as steam treatment (James et al., 2007) and biological control with bacteriophages (Carvalho et al., 2010), but only treatment with water supplemented with chlorine or a chlorinating agent is used commercially. The effects of such decontaminating treatments are limited (Oyarzaball, 2005; Russel and Axtell, 2005). There is, therefore, need for an effective technology that can be operated within commercial constraints.

The role of gas plasmas in microbial inactivation has been studied since the mid $1990 \mathrm{~s}$, but their potential for food decontamination purposes has only recently been recognised. Gas plasmas are usually generated by means of an external electric field; when the voltage applied to a gas exceeds a certain threshold value the gas will become ionized. Gas plasmas comprise mixtures of electrons, ions, atomic species, free radicals and UV photons, all of which have the capability of inactivating micro-organisms (Perni et al., 2007). In order to decontaminate foods without bringing about undesired changes, gas plasmas should ideally be operated at or near room temperature. Until quite recently this could only be achieved under vacuum, which is inconvenient and expensive. Recent advances in plasma source technology allow the generation of plasmas having both spatial and temporal stability at ambient temperatures and atmospheric pressure using relatively simple and inexpensive equipment (Kogelschatz, 2002). Cold atmospheric plasmas have been reported to be very effective against a wide range of microorganisms, including biofilm-formers and bacterial spores (Montie et al., 2000; Deng et 
al., 2005; Vleugels et al., 2005). Although most of the previous work on bacterial inactivation has been conducted with bacteria deposited on the surface of abiotic materials such as membrane filters and glass slides, data on the disinfection of foodstuffs is steadily accumulating. To give examples, Perni et al., (2008b) examined the inactivation of a number of micro-organisms on mango and melon, whilst Kim et al., (2011) reported on the disinfection of bacon.

In the present work, the effectiveness of cold atmospheric plasmas for inactivating Listeria innocua, a non- pathogenic surrogate for Listeria monocytogenes, (Perni et al., 2006) on the surface of both membrane filters and chicken breast (skin and muscle) was examined. A range of plasma operating conditions were first investigated in order to arrive at those that were optimum for the inactivation of $L$. innocua deposited on the surface of membrane filters. Those proving to be the most effective conditions were then applied to chicken skin and then further modified for maximum efficacy. Following this, chicken muscle was treated under these optimised conditions.

\section{Materials and Methods}

\subsection{Microorganisms and Cultivation}

Listeria innocua (ATCC 33090) was stored on cryobeads at $-20{ }^{\circ} \mathrm{C}$. Cells were activated by transferring one of these beads into $100 \mathrm{~mL}$ Tryptone Soy Broth (TSB; Oxoid Ltd., Basingstoke, Hants, UK) in $500 \mathrm{~mL}$ Erlenmeyer flasks and incubating overnight at $30{ }^{\circ} \mathrm{C}$ and 140 rpm. This culture was streaked onto Tryptic Soya Agar plates (TSA; Oxoid Ltd.,) incubated for $24 \mathrm{~h}$ at $30{ }^{\circ} \mathrm{C}$. Working cultures were kept at $4{ }^{\circ} \mathrm{C}$ on TSA slopes, prepared from single colonies of the TSA plates, and subcultured every two weeks. 
Inocula for deposition on the surfaces of membrane filters and chicken tissue were prepared by transferring single colonies from TSA slopes to $500 \mathrm{~mL}$ Erlenmeyer flasks, each containing $100 \mathrm{~mL}$ of TSB. After $24 \mathrm{~h}$ incubation at $30{ }^{\circ} \mathrm{C}$ and $140 \mathrm{rpm}$, a loopful of cells from these cultures was used to inoculate $100 \mathrm{~mL}$ of fresh TSB in $500 \mathrm{~mL}$ Erlenmeyer flasks, incubated as before. Cultivation under these conditions yielded cell populations at stationary phase of growth with a concentration of approximately $5.0 \times 10^{9} \mathrm{CFU} \mathrm{mL}^{-1}$. This second

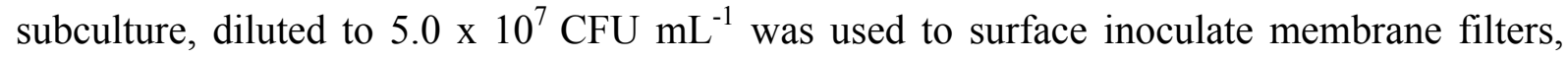
chicken skin and muscle. Additionally, the same culture diluted approximately to $5.0 \times 10^{8}$ CFU mL $\mathrm{m}^{-1}$, was used to load sterile filter papers of $20 \mathrm{~mm}$ diameter (No. 1, Whatman, Fisher Scientific, Loughborough, UK) by immersion in the dilute culture for $15 \mathrm{~min}$. These bacterialaden filters were used to inoculate samples of chicken muscle as described below.

\subsection{Preparation of membrane filters}

For ease of manipulation, $0.20 \mu \mathrm{m}$ pore size Whatman polycarbonate membrane filters of 25 mm diameter (Fisher Scientific, Loughborough, UK) were placed on agar plates (Technical Agar No. 3, Oxoid Ltd.,). Bacterial cell suspension $(100 \mu \mathrm{L})$ was then carefully deposited onto the centre of the sterile membrane filters, and allowed to dry for $60 \mathrm{~min}$. at room temperature in a laminar flow cabinet. All experiments were conducted in triplicate with three independent cultures.

\subsection{Preparation of chicken skin and muscle samples}

Fresh, raw, boneless chicken breasts with the skin attached were purchased at a local supermarket and transported immediately to the laboratory, where they were kept in a refrigerator overnight at $4^{\circ} \mathrm{C}$ before use. The entire skin was removed in one piece from the underlying muscle, using a sterile scalpel and forceps, and placed in Petri dishes. Skin tissue was of two types; rough, relatively thick skin and smoother thinner skin. A slice of 
approximately $2 \mathrm{~mm}$ thickness was cut from the subcutaneous muscle and stored in Petri dishes. Discs of tissue were punched from both muscle and skin pieces using a sterile cork borer of $20 \mathrm{~mm}$ diameter. The resulting discs were placed singly in Petri dishes.

Bacterial suspension $(100 \mu \mathrm{L})$ was deposited onto the centres of the discs of skin and muscle, taking care not to allow the suspension to overflow the edges. After inoculation the tissue samples were kept at room temperature in a laminar flow cabinet for 60 min. to allow attachment. Additionally, bacteria-laden membrane filters (prepared as described above) were pressed lightly onto a dry, sterile filter paper for a few seconds to remove the excess liquid, placed onto prepared chicken samples for 10 min., then carefully removed with forceps. All experiments were conducted in triplicate with three independent cultures.

\subsection{Cold atmospheric plasma apparatus}

The cold atmospheric plasma system comprised a $1.5 \mathrm{~mm}$ inner diameter ceramic tube confining a helium-oxygen flow; a concentric, ring-shaped, $1 \mathrm{~cm}$ wide copper electrode wrapped around the ceramic tube and connected to a high-voltage power supply; and a disc electrode (ground electrode) placed 0.5 to $1.5 \mathrm{~cm}$ downstream of the nozzle of the ceramic tube (Figure 1). The powered electrode was energized with a purpose-built, high-voltage, AC power supply with a peak voltage of 6.5 to $16 \mathrm{kV}$, and a variable excitation frequency between 23 and $38.5 \mathrm{kHz}$. Helium (99.99\% purity) at a fixed flow rate of $5 \mathrm{~L} \mathrm{min.}^{-1}$ and oxygen at a flow rate of up to $100 \mathrm{~mL}$ min. ${ }^{-1}$ were fed through the hollow ceramic tube for ionization. The ionized gas was flushed out of the electrode unit and into ambient air toward a point 0.5 to $1.5 \mathrm{~cm}$ downstream where the samples were placed connected to the ground electrode. In ambient air, the gas plasma appeared as a pale purple plume, termed a cold atmospheric plasma pen (CAP-Pen).

\subsection{Microbial inactivation procedure and cell recovery}


The CAP-Pen diameter of $3 \mathrm{~mm}$ was much smaller than the bacterial deposition area (approx. $1 \mathrm{~cm}$ in diameter), therefore plasma treatment was effected by keeping the plasma nozzle fixed and moving the sample beneath it in a zig-zag path by hand so that the entire surface was exposed to the plume. The duration of CAP-Pen treatment varied from $10 \mathrm{~s}$ to 8 min. These total treatment times were about 10 fold greater than the time that any part of the treated area was exposed to the plasma. Therefore it should be noted the $\mathrm{D}$ values quoted are in reality apparent D values. Following CAP-Pen treatment, cells were recovered from membrane filters by transferring them to sterile Universal bottles containing $10 \mathrm{~mL}$ of Ringers solution (Oxoid Ltd.) and agitating for $30 \mathrm{~s}$ with a vortex mixer. Chicken samples were transferred to stomacher bags containing $10 \mathrm{~mL}$ of sterile Ringers solution and surviving cells were recovered by treating for $30 \mathrm{~s}$ in the Stomacher 400 (Seward Ltd., Thetford, Norfolk, UK) at intermediate speed. Aliquots $(100 \mu \mathrm{L})$ of cell suspension or serial dilutions in Ringers solution were spread onto agar plates. Total bacterial counts were determined on TSA plates incubated at $30{ }^{\circ} \mathrm{C}$ for $24 \mathrm{~h}$. L. innocua was enumerated on PALCAM Listeria selective agar base (Oxoid Ltd), supplemented with PALCAM Listeria selective supplement (Oxoid Ltd.). The plates were incubated at $30{ }^{\circ} \mathrm{C}$ for $48 \mathrm{~h}$. All counts were performed in triplicate, and all the results reported here as CFU per square centimetre are mean values.

\subsection{Mathematical Modelling of Bacterial Inactivation}

The Baranyi inactivation model as modified by Xiong et al., (1989) was applied to all of the data presented here. This was done according to the form of the inactivation curve, and either applied to the entire data (in experiments I, II, V-VII) or, where more than one phase existed, to individual phases (in experiments III and IV). D values, the times required for one logreduction of the microbial population, were calculated from the corresponding inactivation rate constants $(\mathrm{k})$ i.e. $\mathrm{D}=2.303 / \mathrm{k}$. 


\subsection{Scanning electron microscopy (SEM)}

Skin and muscle samples were prepared for SEM by chemically fixing them in $0.025 \mathrm{M}$ phosphate buffer ( $\mathrm{pH}$ 6.8) containing $3 \%\left(\mathrm{v} \mathrm{v}^{-1}\right)$ glutaraldehyde for $1 \mathrm{~h}$. Samples were then washed twice for $15 \mathrm{~min}$. in the same phosphate buffer prior to dehydration in a series of increasing ethanol concentrations $\left(20,40,60,80\right.$ and $100 \% \mathrm{v} \mathrm{v}^{-1}$ ethanol in water; $15 \mathrm{~min}$. in each solution). Then, samples were transferred from $100 \%$ ethanol to $100 \%$ acetone in a similar way $\left(30,50,70,90\right.$ and $100 \% \mathrm{v} \mathrm{v}^{-1}$ acetone in ethanol; $10 \mathrm{~min}$. in each solution) and dried by critical point-drying with liquid $\mathrm{CO}_{2}$ (Balzers CPD 030, BAL-TEC AG, Fürstentum, Liechtenstein). Membrane filters were also subjected to chemical fixation, but they were first dehydrated by incubation at $60{ }^{\circ} \mathrm{C}$ overnight. Following this, all the samples were mounted on aluminium stubs with double-sided carbon sticky-tape, sputtered with gold in a vacuum evaporator (Balzers SCD 004, BAL-TEC AG, Fürstentum, Liechtenstein), and visualized using a JEOL-6100 SEM microscope (JEOL Ltd., Tokyo, Japan).

\subsection{Statistical analysis}

Comparisons of experimental data, either in the form of log concentrations or log reductions, were evaluated by means of analysis of variance (ANOVA) tests. The multiple Range Test was used to distinguish means which differed significantly from each other. Standardized skewness and standardized kurtosis were used to assess if data sets were normally distributed.

These analyses were performed using STATGRAPHICS PLUS for Windows $3.0^{\circledR}$ Package (Statistical Graphics, Washington, USA). Test statistics were regarded as significant when $p$ was $<0.05$.

\section{Results and Discussion}




\subsection{Inactivation on membrane filters}

Plasma inactivation of L. innocua deposited on membrane filters at a range of experimental conditions is shown in Figure 2 and Table 1. The temperature of samples undergoing treatment never exceeded $30^{\circ} \mathrm{C}$. Increasing the peak voltage, whilst maintaining the gap distance at $1.5 \mathrm{~cm}$, had relatively little effect. However, decreasing the gap distance to $1.0 \mathrm{~cm}$ resulted in a biphasic inactivation curve in contrast to the monophasic curves obtained for experiments I and II. A substantial reduction in D value for the first phase of inactivation was followed by a second phase that had a $\mathrm{D}$ value almost one order of magnitude greater. This pattern of inactivation was maintained as the voltage was further increased to $7.0 \mathrm{kV}$ with a reduction in $\mathrm{D}$ value for both phases of the inactivation curve. Further increasing the voltage to $8.0 \mathrm{kV}$ resulted in a return to monophasic inactivation kinetics, and a reduction in the $\mathrm{D}$ value to $4.5 \mathrm{~s}$. Increasing the voltage still further necessitated a decrease in frequency to 23.0 $\mathrm{kHz}$ in order to maintain stable plasma operation. under these conditions oxygen was supplied to the CAP. This yielded a D value of $3.4 \mathrm{~s}$. at a peak voltage of $9.0 \mathrm{kV}$ and $3.1 \mathrm{~s}$. at $11.0 \mathrm{kV}$. Table 2 shows that L. innocua was inactivated to below the detection limit $\left(1 \times 10^{3} \mathrm{CFU} \mathrm{cm}^{-2}\right)$ after only 10 s treatment in experiments V, VI and VII. Inactivation curves displaying biphasic (or even multiphasic) behaviour have previously been interpreted as being indicative of the occurrence of inactivation by different plasma species (Montie et al., 2000; Moisan et al., 2001; Kong et al., 2009; Kong et al., 2005).

Perni et al. (2008b) reported that $1.5 \mathrm{~s}$ of plasma exposure were sufficient to inactivate $L$. monocytogenes on membrane filters $\left(\approx 4 \times 10^{6} \mathrm{CFU} / \mathrm{cm}^{2}\right)$ to below the detection limit, although their treatment conditions $\left(30 \mathrm{kHz}, 8 \mathrm{kV}\right.$ and $25 \mathrm{~mL}$ oxygen $\left.\min ^{-1}\right)$ were not identical to those employed here. Plasma exposure time to achieve no detectable cell counts was of the same order for both species, although the slightly higher value obtained here 
210 indicates that $L$. innocua may be marginally more resistant to plasma treatment than is $L$.

211

212 monocytogenes.

When oxygen was added to the helium flow (experiments VI and VII), peak voltage and excitation frequency had to be re-set to achieve stable plasma operation. Molecular gases have higher breakdown voltages than atomic gases, and therefore the applied voltage had to be increased when oxygen was mixed with helium. For the CAP-pen used here it was necessary to increase the voltage to $9 \mathrm{kV}$ at an excitation frequency of $38.5 \mathrm{kHz}$. However, this was found to result in considerable overheating in, and subsequent failure of, the transformer used in the power supply. To prevent overheating the excitation frequency was reduced to $23 \mathrm{kHz}$ and this resulted in stable operation. The key parameter for comparing the lethality of plasmas is the number densities of the relevant biocidal plasma species. These were taken to be oxygen atoms since they had previously been identified as a key biocidal species in atmospheric $\mathrm{He}-\mathrm{O}_{2}$ plasmas (Deng et al.,2007a). The optical emission intensities at $777 \mathrm{~nm}$ and $845 \mathrm{~nm}$ (not shown here) were taken as an indirect indicator of atomic oxygen concentrations. Using this criterion, conditions in experiment IV and V were found to be similar to those in VI and VII, respectively. Moreover, previous studies have shown that plasma characteristics do not change in any significant way in the frequency range of 20 to $50 \mathrm{kHz}$ (Deng and Kong, 2004).

Although the D values were of the same order of magnitude, $\log$ reductions at $10 \mathrm{~s}$ in experiments VI and VII were significantly different to the inactivation achieved in the absence of oxygen (experiment V). Therefore, carrier gas composition played a decisive role in plasma inactivation as would be expected (Deng et al., 2007b; Perni et al., 2007).

\subsection{Inactivation on skin from chicken breast}


235 Viable counts recovered from chicken skin before inoculation were of the order of $4.0 \times 10^{5}$

CFU $\mathrm{cm}^{2}$, but did not include listeriae. Viable counts after CAP-Pen decontamination of inoculated skin under various experimental conditions are shown in Table 2. The plasma operating parameters that were most effective with membrane filters were applied to the treatment of chicken skin. However, the dielectric properties of membranes and chicken skin are different, and this necessitated adjustment of the operating conditions in order to achieve stable operation. In particular, different peak voltages, excitation frequencies, carrier gas and plume length (experiments IV to VIII) were tested within the plasma stability range, in addition to studying the effect of cell attachment (experiment IX) as well as skin type (experiment III).

Reductions in viable counts were considerably below those achieved using membranes, and the D values were correspondingly higher. In experiments I to III, skin samples were treated of up to 4 min. were achieved. Therefore in subsequent experiments treatment was for $8 \mathrm{~min}$. only.

Experiments I and II were conducted under conditions previously identified as representing the best conditions for inactivation on membrane filters (V and VII, respectively). After 4 min., the conditions in experiment II resulted in significantly increased log reductions of the total microflora, but not of L. innocua. However, after $8 \mathrm{~min}$. of exposure, there were significant decreases in numbers of both the total microflora and L. innocua. Curiously, higher levels of inactivation were achieved in the absence of oxygen in the carrier gas (experiment I), which contrasts with the results obtained using membrane filters. When experiments I and II are compared to experiments conducted with membrane filters under the 
same conditions (V and VII, respectively), significantly higher $(\mathrm{p}<0.05) \mathrm{D}$ values (approx. 200 and 600 fold higher, respectively) and $\log$ reductions (4- and 15- fold higher, respectively) were achieved with membrane filters with much shorter contact times. Thus chicken skin exerts a protective effect on microorganisms present at the surface.

The effect of skin type i.e. thick rough skin versus thin and relatively smooth skin, on plasma effectiveness was revealed as negligible from experiments II and III, since no significant differences $(p>0.05)$ were found in log reductions at any of the treatment times.

High excitation frequencies have been reported to expand the plasma stability range and enable more abundant reactive plasma species, such as oxygen atoms and hydroxyl radicals to be generated, and this has been correlated with increased anti-microbial efficiency of plasmas (Walsh and Kong, 2006). The importance of this parameter, at constant peak voltage, is evident by comparing experiments II and IV, since significantly higher reductions $(\mathrm{p}<$ 0.05)were achieved at the highest than at the lower frequencies for both total and listerial populations.

Increasing the oxygen flow rate whilst maintaining all other parameters constant resulted in a significant reduction in $\mathrm{D}$ values, as is evident by comparing the results for experiments $\mathrm{V}$ and VI. The D value for the latter experiment was not significantly different to that obtained in experiment I. However, when the oxygen flow was set at $100 \mathrm{~mL} \mathrm{min.}{ }^{-1}$ (experiment VII), more effective inactivation was achieved than in experiment VI. To try to improve plasma effectiveness, the distance between the plasma source and the chicken skin (the 'gap' in Table 2) was decreased to $0.5 \mathrm{~cm}$ (experiment VIII). Significantly lower log reductions $(\mathrm{p}<0.05)$ were achieved for L. innocua and total microflora as compared to experiment VII, although reductions were comparable to those in experiments I, and IV to VI. However, D values for total counts and L. innocua in experiment VIII were not significantly different $(\mathrm{p}>0.05)$ from 
the corresponding values in experiment VII. Cell migration into skin tissue during attachment may have occurred and this could well have affected plasma effectiveness, since cells could be transported beyond the reach of plasma species as Perni et al. (2008b) demonstrated for the plasma treatment of fresh cut fruit surfaces. To confirm this supposition, samples were treated immediately after deposition onto chicken skin (experiment IX) under the same conditions as in experiment VII. D values for total and listerial counts were not significantly different $(\mathrm{p}>$ 0.05) between experiments VII and IX. For these same experiments, no significant differences were found between $\log$ reductions of $L$. innocua, whereas values for the total microflora were significantly lower $(\mathrm{p}<0.05)$, although they were of the same order as for experiments I, IV to VI and VIII.

Plasma conditions in experiment VII resulted in the most effective inactivation of L. innocua on chicken breast skin with a reduction of just under $1 \log$ and a $\mathrm{D}$ value of about $9 \mathrm{~min}$.

\subsection{Inactivation on chicken breast muscle}

Chicken skin acts as a physical barrier to microbial migration into the inner tissues, but severed blood vessels or skin cut during skinning, boning and portioning may contaminate the underlying tissue (Avens et al., 2002). Microbiological analysis of uninoculated muscle

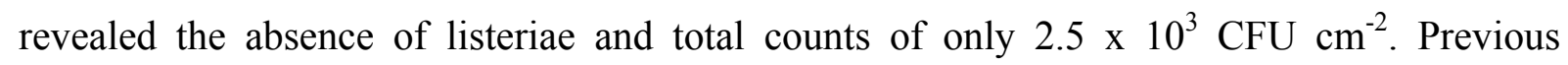
experiments conducted with plasma membranes and chicken skin allowed identification of plasma operating conditions that are more effective for inactivation. These were applied to the treatment of chicken muscle (Table 3).

In experiment I, no significant differences $(p>0.05)$ were observed after 8 min. of exposure, when compared to the initial concentration, whereas significant reduction in numbers was achieved in experiment II. However, microbial response to plasma treatment was markedly 
different in experiment III. The survival curve (not shown) displayed biphasic behaviour, with a turning point at $10 \mathrm{~s}$ of CAP-Pen exposure, although significant differences were not found between both D values in the overall comparison. Log reductions in experiments I, II and III at 8 min. of plasma exposure, were significantly different $(p<0.05)$, with a much higher inactivation having been achieved in experiment III than in I and II (55-fold and 8-fold higher, respectively). Such a markedly different cell response to plasma treatment may be a reflection of differences in the inoculation procedure (direct deposition in experiment I and II versus filter contact in III), since plasma effectiveness has been reported to depend on the cell exposure method (Kong et al., 2005; Kong et al., 2009).

Significantly lower log reductions and higher D values were achieved with chicken muscle in experiment I (in the absence of oxygen), when compared to the same conditions on membrane filters (experiment V, Table 1) and skin (experiment I, Table 2). However, when compared with experiment II and the corresponding treatment on chicken skin (experiment IV), no significant differences were found. Therefore, the presence of oxygen in the carrier gas played a more decisive role on muscle than on skin, since inactivation in experiment II was sevenfold higher than in experiment I, whereas similar inactivation was achieved between skin experiments I and IV. Finally, log reductions in muscle experiment III were significantly higher than the values obtained for the corresponding skin experiment (VII).

Although the level of inactivation of $L$. innocua achieved on chicken muscle was lower than that on membrane filters, the highest level achieved, approximately $3.3 \log$ reductions, would undoubtedly be of commercial interest.

\subsection{Plasma effectiveness and surface topography}

Whereas all experiments were conducted under broadly similar conditions, the effectiveness of plasma treatment decreased in the transition from membrane filters to chicken muscle, and 
330 from that to chicken skin. This is strongly suggestive that surface topography plays a

significant role in inactivation using gas plasmas. An average of $5.2 \times 10^{6}$ cells were deposited on each membrane, and from theoretical considerations based on the dimensions of L. innocua cells (assumed to be cylinders with dimensions of $1 \mu \mathrm{m} \times 0.5 \mu \mathrm{m}$ ) and the membrane surface area $\left(1 \mathrm{~cm}^{2}\right)$ stacking would start to occur only as the cells exceeded a concentration in excess of $2 \times 10^{7}$ cells. Therefore, we can be reasonably certain that all cells on the surface of the membrane were equally exposed to the gaseous plasma species.

An SEM image of skin removed from chicken breast is shown in Figure 3a, and reveals a highly irregular topography. It is significant that SEMs taken after inoculation of the skin with L. innocua did not reveal the presence of an abundance of bacteria at the surface. In Figure $3 \mathrm{~b}$ for example, only a small cluster of cells is visible slightly to the right of the centre of the image. It is possible that bacteria which were deposited at the surface were drawn through capillary action into feather follicles and other surface irregularities. Kim et al. (1996) reported that bacteria could migrate from the surface to depths up to about $140 \mu \mathrm{m}$. Microorganisms at these distances from the surface have previously been reported to be largely unaffected by either thermal or chemical treatments. Moreover, the highest levels of inactivation achieved by these methods was typically no more than 1 log-reduction (Thomas and McMeekin, 1980), the maximum value reported in this work.

The surface of the chicken muscle immediately following the two different inoculation procedures employed here is shown in Figures $4 \mathrm{a}$ and $4 \mathrm{~b}$, the former was obtained after direct deposition, and the latter following filter contact. Figure 4a clearly reveals the presence of fissures. As rigor develops, muscle fibres have been reported to undergo radial shrinkage, and pull away from surrounding connective tissue (Frank, 2001). The resulting fissures, which 
could provide a route for bacterial penetration, may be enlarged in the presence of excess water. Direct deposition causes the tissue to take up water and swell and this could cause bacteria to be drawn into the tissues with the water and become entrapped between swollen fibres. It has been reported that bacteria may be carried to depths of up to $25 \mu \mathrm{m}$ by this means (Thomas and McMeekin, 1987; Auty et al., 2005). However, after inoculation by filter contact, a dense fibre network covering the muscle surface was observed (Figure 4b), and this possibly prevented cell migration through these channels. Figures $4 \mathrm{c}$ and $4 \mathrm{~d}$ reveal bacteria concentrated around irregularities at the surface of chicken muscle. Some of these cells would presumably still be vulnerable to plasma species, but others might be protected by cells situated above them.

\subsection{Prospects for employing gas plasmas for the decontamination of chicken tissue}

This work has demonstrated that cold atmospheric gas plasmas have the potential to decontaminate chicken muscle. The results obtained with chicken skin are comparable to those obtained by other techniques that fall under the category of minimal processing and are testament to the difficulties in decontaminating this type of tissue owing to its topography. The plasma device employed was a laboratory model and treatment of chicken on a commercial scale would require the issue of scale-up to be addressed. Advances in this direction are already being made; Cao et al., (2010) have described the construction of a socalled '2-D plasma brush' that comprises multiple plasma plumes. Treatment times with such a device would be significantly reduced over those quoted above, and further scale-up would result in a concomitant decrease in the times necessary to bring about the requisite level of surface decontamination in industrial settings. 
The chemical species formed during plasma treatment are highly reactive, and as a result, very short-lived. Therefore treatment with gas plasmas should not result in the formation of compounds that could be viewed as residues. However, it remains necessary to assess the effects of plasma treatment on the sensory and nutritional properties of the foods undergoing treatment in a systematic and exhaustive manner. Such studies were beyond the scope of the present work, although treatment as described above did not result in any obvious changes to the appearance of the chicken muscle or skin.

Lastly, it would be important to take into account consumer perception of any novel decontamination technology and before commercialisation of plasma treatment in the food industry could become a reality, this would need to be addressed.

\section{ACKNOWLEDGEMENTS}

This work was financially supported by FICYT (Foundation for Scientific and Technical Research, Asturias, Spain) and MEC (Ministry of Education and Science). The authors would like to thank the Scanning Electron Microscopy service of the University of Oviedo for the assistance provided.

\section{REFERENCES}

Auty, M., G. Duffy, D. O’beirne, A. McGovern, E. Gleeson, and K. Jordan. 2005. In situ localization of Escherichia coli $0157: \mathrm{H} 7$ in food by confocal scanning laser microscopy. J. Food Prot. 68,482-486.

Avens, J. S., S. N. Albright, A. S. Morton, B. E. Prewitt, P. A. Kendall, and J. N. Sofos. 2002. Destruction of microorganisms on chicken carcasses by steam and boiling water immersion. Food Con. 13, 445-450. 
Cao, Z., Nie, Q., Bayliss, D.L., Walsh, J.L., Ren, C.S., Wang, D. Z., and Kong, M.G. 2010.

Spatially extended atmospheric plasma arrays. Plasma Sources Sci. Technol. 19, 025003.

Carvalho, CM; Gannon, BW; Halfhide, DE, Santos, S.B., Hayes, C.M., Roe, J.M., Azeredo, J. 2010. The in vivo efficacy of two administration routes of a phage cocktail to reduce numbers of Campylobacter coli and Campylobacter jejuni in chickens. BMC Microbiol. 10, Article Number: 232.

Deng, X. T., and Kong, M.G. 2004. Frequency range for stable generation of atmospheric glow discharges in He and $\mathrm{N}_{2}$. IEEE Trans. Plasma Sci. 32, 1709-1715.

Deng, X. T., Shi, J. J., and Kong, M.G. 2007a. Protein inactivation by atmospheric pressure glow discharges: capability and mechanisms. J. Appl. Phys. 101, 074701.

Deng, S., R. Ruan, C. K. Mok, G. Huang, X. Lin, and P. Chen. 2007b. Inactivation of Escherichia coli on almonds using non-thermal plasma. J. Food Sci. 72, M62-M66.

Deng, X. T., J. J. Shi, G. Shama, and M. G. Kong. 2005. Effects of microbial loading and sporulation temperature on atmospheric plasma inactivation of Bacillus subtilis spores. Appl. Phys. Lett. 87,153901.

Frank, J. F. 2001. Microbial attachment to food and food contact surfaces. Adv. Food Nutr. Res. 43, 319-370.

Jacobsreitsma, W.F., Bolder, N.M., Mulder, R.W.A.W. 1994. Cecal Carriage of Campylobacter and Salmonella in Dutch Broiler Flocks at Slaughter - A One-Year Study Poultry Sci. 73, 1260-1266.

James, C., James, S.J., Hannay, N., Purnell, G., Barbedo-Pinto, C., Yaman, H., Araujo, M., Kim, B., Yun, H., Jung S., Jung, Y., Jung, H., Choe, W., and Jo, C. 2011. Effect of atmospheric pressure plasma on inactivation of pathogens inoculated onto bacon using two different gas compositions. Food Microbiol. 28, 9-13. 
Kim, K. Y., J. F. Frank, and S. E. Craven. 1996. Three-dimensional visualization of Salmonella typhimurium to poultry skin using confocal scanning laser microscopy. Lett. Appl. Microbiol. 22, 280-282.

Kogelschatz, U. 2002. Filamentary, patterned, and diffuse barrier discharges. IEEE Trans. Plasma Sci. 30,1400-1408.

Kong, M.G., Kroensen, G. M. W., Morfill, G. E., Nosenko, T., Shimizu, T., van Dijk, J., and Zimmermann, J. L. 2009. Plasma medicine - an introductory review. New J. Phys. 11, 115012.

Moisan, M., J. Barbeau, S. Moreau, J. Pelletier, M. Tabrizian, and L'H. Yahia. 2001. Lowtemperature sterilization using gas plasmas: a review of the experiments and an analysis of the inactivation mechanisms. Int. J. Pharm. 226, 1-21.

Montie, T. C., K. Kelly-Wintenberg, and J. R. Roth. 2000. An overview of research using the one atmosphere uniform glow discharge plasma (OAUGDP) for sterilization of surfaces and materials. IEEE Trans. Plasma Sci. 28, 41-50.

Murphy, R.Y., Osaili, T., Duncan, L.K., and Marcy, J. A. 2004. Thermal inactivation of Salmonella and Listeria monocytogenes in ground chicken thigh/leg meat and skin. Poultry Sci. $83,1218-1225$.

Oyarzabal, O.A. 2005. Reduction of Campylobacter spp. by commercial antimicrobials applied during the processing of broiler chickens: A review from the United States perspective. J. Food Prot. 68, 1752-1760.

Perni, S., Jordan, S.J., Andrew, P.W., and Shama, G. 2006. Biofilm development by Listeria innocua in turbulent flow regimes. Food Con. 17, 875-883.

Perni, S., G. Shama, J. L. Hobman, P. A. Lund, C. J. Kershaw, G. A. Hidalgo-Arroyo, C. W. Penn, X. T. Deng, J. L. Walsh, and M. G. Kong. 2007. Probing bactericidal mechanisms 
induced by cold atmospheric plasmas with Escherichia coli mutants. Appl. Phys. Lett. 90, 073902.

Perni, S., D. W. Liu, G. Shama, and M. G. Kong. 2008a. Cold atmospheric plasma decontamination of the pericarps of fruit. J. Food Protect. 71, 302-308.

Perni, S., G. Shama, and M. G. Kong. 2008b. Cold atmospheric plasma disinfection of cut fruit surfaces contaminated with migrating microorganisms. J. Food Protect. 71,1619-1625.

Rodriguez De Ledesma, A.M., Riemann, H.P., Farver, T. B. 1996. Short-time treatment with alkali and/or hot water to remove common pathogenic and spoilage bacteria from chicken wing skin. J. Food Prot. 59, 746-750.

Russell, S.M., Axtell, S.P. 2005. Monochloramine versus sodium hypochlorite as antimicrobial agents for reducing populations of bacteria on broiler chicken carcasses. J. Food Prot. 68, 758-763.

Thomas, C. J., and T. A. McMeekin. 1980. Contamination of broiler carcass skin during commercial processing procedures: an electron microscopic study. Appl. Env. Microb. 40, 133-144.

Thomas, C. J., R. D. O'Rourke, and T. A. McMeekin. 1987. Bacterial penetration of chicken breast muscle. Food Microbiol. 4, 87-95.

Vleugels, M., G. Shama, X. T. Deng, E. Greenacre, T. Brocklehurst, and M. G. Kong. 2005. Atmospheric plasma inactivation of biofilm-forming bacteria for food safety control. IEEE Trans. Plasma Sci. 33, 824-828.

Walsh, J. L., and M. G. Kong. 2006. Sharp bursts of high-flux reactive species in submicrosecond pulsed atmospheric pressure glow discharges. Appl. Phys. Lett. 89, 231503. 
471 Xiong, R., G. Xie, A. S. Edmondson, R. H. Linton, and M. A. Sheard. 1999. Comparison of 472 the Baranyi model with the modified Gompertz equation for modeling thermal inactivation of 473 Listeria monocytogenes Scott A. Food Microbiol. 16, 269-279. 


\section{FIGURE CAPTIONS}

Figure 1. Schematic of the cold atmospheric plasma pen (CAP-Pen) apparatus

Figure 2. Plasma inactivation of Listeria innocua deposited on the surface of membrane filters: $\bigcirc$-experiment I; $\boldsymbol{\Delta}$-experiment II; $\boldsymbol{\Delta}$-experiment III; $\diamond$-experiment IV; $\boldsymbol{\square}$-experiment V; $>$-experiment VI; - -experiment VII (see experimental conditions in Table 1). Dashed lines correspond to concentrations below the detection limit.Figure 3. Scanning electron micrographs. a) non-inoculated skin sample (x1000 magnification), b) cluster of bacteria present on inoculated skin (x1000 magnification).

Figure 4. Scanning electron micrographs a) muscle sample newly inoculated by aliquot deposition (x2500 magnification), b) muscle sample newly inoculated by filter contact (x2000 magnification) and C) and D) muscle sample inoculated by filter contact after $24 \mathrm{~h}$ of incubation at $25^{\circ} \mathrm{C}$ (x 2000 and x 6000 magnification, respectively).

9

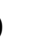

(1)

(1)

(

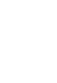


FIGURE 1

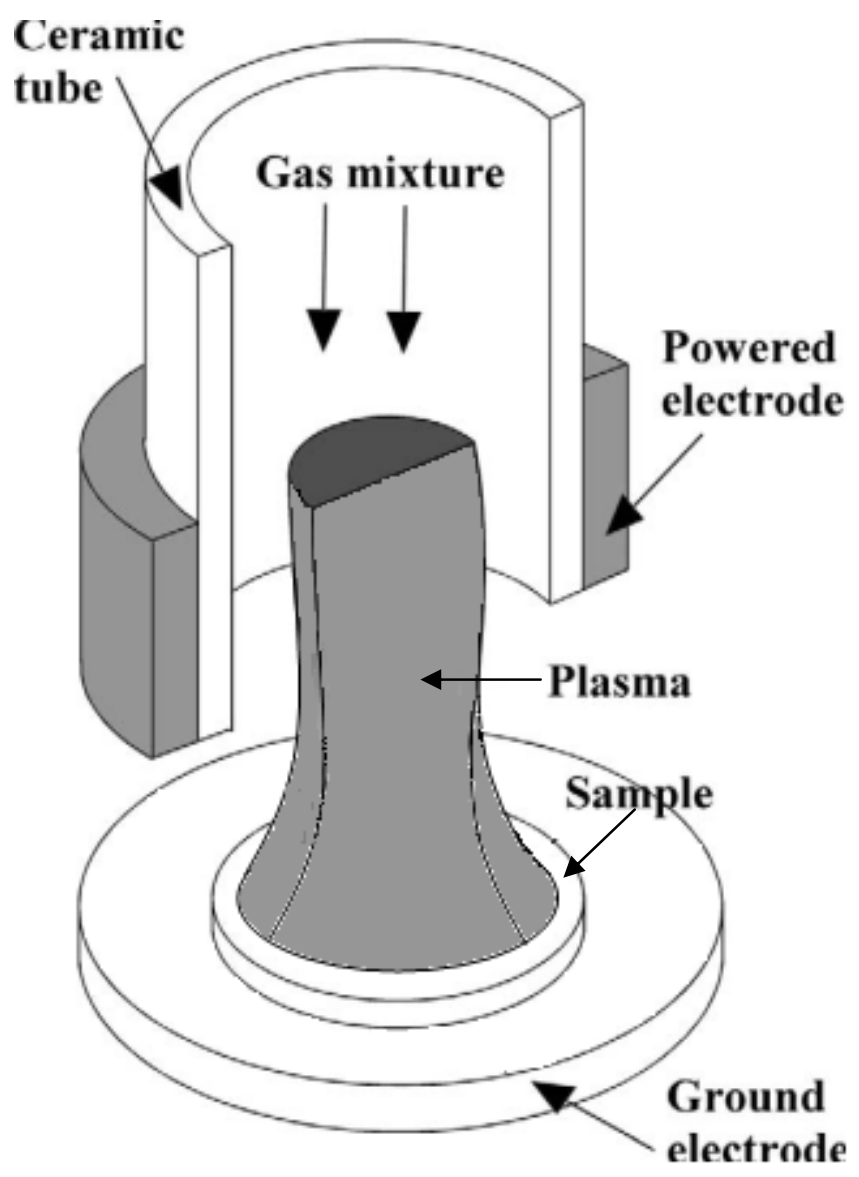


FIGURE 2

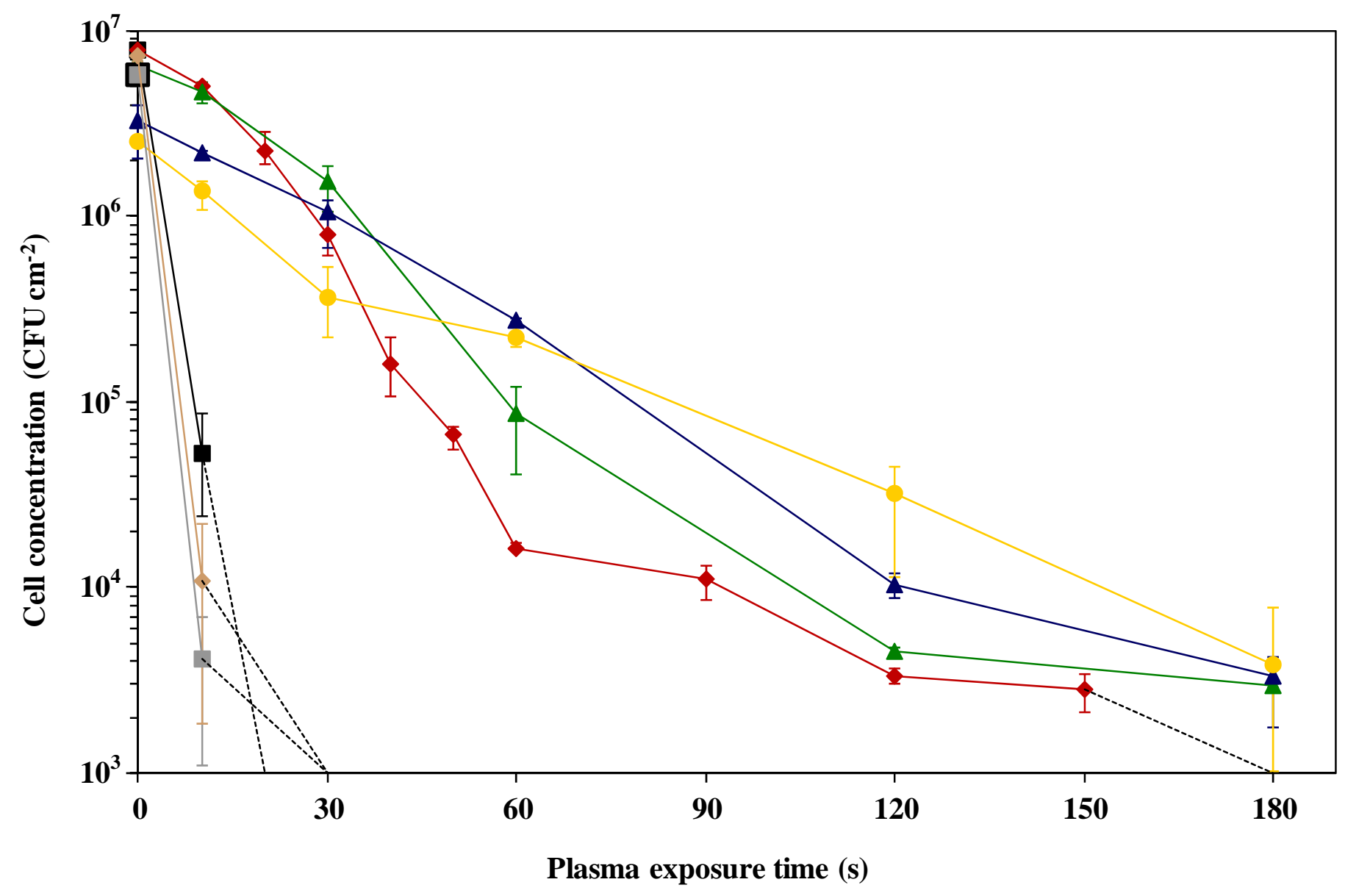


TABLE 1. Inactivation of Listeria innocua deposited on membrane filters

\begin{tabular}{|c|c|c|c|c|c|c|c|c|c|c|c|}
\hline \multirow{3}{*}{$\begin{array}{l}\text { Exp. }^{1} \\
I_{(a)}\end{array}$} & \multicolumn{5}{|c|}{ CAP-Pen Treatment Conditions } & \multicolumn{5}{|c|}{$\begin{array}{c}\text { Log-reductions } \\
\quad\left(\log C F U / \mathrm{cm}^{2}\right)\end{array}$} & \multirow{2}{*}{$\begin{array}{c}\text { D-values } \\
(\mathrm{s})\end{array}$} \\
\hline & $\begin{array}{l}\text { Gap } \\
(\mathrm{cm})\end{array}$ & $\begin{array}{c}\text { Voltage } \\
(\mathrm{kV})\end{array}$ & $\begin{array}{l}\text { Frequency } \\
\quad(\mathrm{kHz})\end{array}$ & $\begin{array}{c}\mathbf{H e} \\
(\mathrm{L} / \mathrm{min})\end{array}$ & $\underset{(\mathrm{mL} / \mathrm{min})}{\mathbf{O}_{2}}$ & $10 \mathrm{~s}$ & $30 \mathrm{~s}$ & $1 \mathrm{~min}$ & $2 \min$ & $3 \mathrm{~min}$ & \\
\hline & 1.5 & 6.0 & 38.5 & 5.0 & 0.0 & $0.27 \pm 0.07^{\mathbf{a}}{ }_{\mathbf{A}}$ & $0.86 \pm 0.17_{\mathbf{A}}^{\mathbf{b}}$ & $1.05 \pm 0.03^{\mathbf{b}}$ & $1.96 \pm 0.31_{\mathrm{A}}^{\mathrm{C}}$ & $2.95 \pm 0.40^{\mathbf{d}}{ }_{\mathbf{A}}$ & $60.7 \pm 7.8^{\mathbf{a}}$ \\
\hline $\mathbf{I I}_{(\mathbf{a})}$ & 1.5 & 6.5 & 38.5 & 5.0 & 0.0 & $0.16 \pm 0.14^{\mathrm{a}}{ }_{\mathrm{A}}$ & $0.49 \pm 0.01^{\mathbf{b}}{ }_{\mathbf{B}}$ & $1.05 \pm 0.15^{\mathbf{C}}$ & $2.48 \pm 0.10^{\mathbf{d}}{ }_{\mathbf{B}}$ & $3.00 \pm 0.06_{\mathrm{A}}^{\mathbf{e}}$ & $56.0 \pm 0.8^{\mathbf{a}, \mathbf{b}}$ \\
\hline III $_{(\mathbf{b}, \mathbf{c})}$ & 1.0 & 6.5 & 38.5 & 5.0 & 0.0 & $0.15 \pm 0.04_{\mathrm{A}}^{\mathrm{a}}$ & $0.63 \pm 0.12^{\mathbf{b}}{ }_{\mathbf{B}}$ & $1.92 \pm 0.23^{\mathbf{C}}$ & $3.15 \pm 0.01^{d}{ }_{C}$ & $3.34 \pm 0.01^{\mathbf{d}}{ }_{\mathrm{A}}$ & $\begin{aligned} 37.0 & \pm 1.4^{\mathbf{b , c}} \\
* 322.1 & \pm 35.1^{\mathbf{d}}\end{aligned}$ \\
\hline $\mathbf{I V}_{(\mathbf{b})}$ & 1.0 & 7.0 & 38.5 & 5.0 & 0.0 & $0.19 \pm 0.01^{\mathbf{a}}{ }_{\mathrm{A}}$ & $1.01 \pm 0.10^{\mathbf{b}}{ }_{\mathrm{A}}$ & $2.68 \pm 0.01^{\mathrm{c}} \mathrm{C}$ & $3.37 \pm 0.03^{\mathbf{d}} \mathbf{C}$ & ND & $\begin{array}{r}24.2 \pm 0.8^{\mathbf{c}, \mathbf{e}} \\
{ }^{*} 108.5 \pm 10.2^{\mathbf{f}}\end{array}$ \\
\hline$V_{(b)}$ & 1.0 & 8.0 & 38.5 & 5.0 & 0.0 & $2.23 \pm 0.23_{\mathbf{B}}$ & ND & ND & ND & ND & $4.5 \pm 0.5^{\mathbf{e}}$ \\
\hline $\mathrm{VI}_{(\mathbf{b}, \mathbf{c})}$ & 1.0 & 9.0 & 23.0 & 5.0 & 25.0 & $3.02 \pm 0.51_{C}$ & ND & ND & ND & ND & $3.4 \pm 0.6^{\mathbf{e}}$ \\
\hline $\mathrm{VII}_{(\mathbf{c})}$ & 1.0 & 11.0 & 23.0 & 5.0 & 25.0 & $3.26 \pm 0.37_{C}$ & ND & ND & ND & ND & $3.1 \pm 0.3^{\mathbf{e}}$ \\
\hline
\end{tabular}

ND: not detectable (detection limit, $1 \times 10^{3} \mathrm{CFU} / \mathrm{cm}^{2}$ )

${ }^{1}$ Initial viable counts of experiments lacking common letters are significantly different $(\mathrm{P} \leq 0.05)$.

${ }^{2}$ Within the same row (same experiment), log-reductions bearing different superscripts are significantly different $(\mathrm{P} \leq 0.05)$.

${ }^{3}$ Within the same column (same exposure time), log-reductions bearing different subscripts are significantly different $(\mathrm{P} \leq 0.05)$.

${ }^{4} \mathrm{D}$-values bearing different superscripts are significantly different $(\mathrm{P} \leq 0.05)$.

*D-values of the second phase (biphasic survival curves) 
TABLE 2. Inactivation of Listeria innocua and total microflora on the skin of chicken breasts

\section{CAP-Pen Treatment Conditions ${ }^{+}$}

Exp.

$\overline{\text { I }}$

Gap Voltage Frequency $\mathrm{O}_{2} \quad$ Skin

$\begin{array}{llll}(\mathrm{cm}) & (\mathrm{kV}) & (\mathrm{kHz}) & (\mathrm{mL} / \mathrm{min}) \\ \mathbf{t y p e}\end{array}$

II

III

\begin{tabular}{l} 
IV \\
\hline V \\
\hline
\end{tabular}

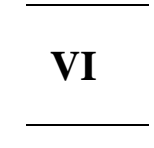

8.0

\begin{tabular}{lllll}
1.0 & 8.0 & 38.5 & 0.0 & Rough \\
\hline
\end{tabular}

\section{VII}

$1.0 \quad 11$

\begin{tabular}{lllll}
\hline 1.0 & 11.0 & 23.0 & 25.0 & Smooth \\
\hline
\end{tabular}

\begin{tabular}{lllll}
\hline 1.0 & 11.0 & 30.0 & 25.0 & Rough \\
\hline
\end{tabular}

\begin{tabular}{lllll}
\hline 1.0 & 16.0 & 30.0 & 25.0 & Rough \\
\hline
\end{tabular}

\begin{tabular}{lllll}
\hline 1.0 & 16.0 & 30.0 & 50.0 & Rough \\
\hline
\end{tabular}

\section{VIII}

\begin{tabular}{lllll}
1.0 & 16.0 & 30.0 & 100.0 & Rough \\
\hline 0.5 & 16.0 & 30.0 & 100.0 & Rough
\end{tabular}

IX*

\begin{tabular}{lllll}
0.5 & 16.0 & 30.0 & 100.0 & Rough \\
\hline 1.0 & 16.0 & 30.0 & 100.0 & Rough
\end{tabular}

\begin{tabular}{|c|c|c|c|c|}
\hline \multicolumn{4}{|c|}{ Log-reductions $\left(\log \mathrm{CFU} / \mathrm{cm}^{2}\right)^{1,2,3}$} & \multirow{3}{*}{$\begin{array}{c}\begin{array}{c}\text { D-values } \\
\text { (min.) }\end{array} \\
\text { (tsterta }\end{array}$} \\
\hline \multicolumn{2}{|c|}{4 min exposure } & \multicolumn{2}{|c|}{8 min exposure } & \\
\hline Total & Listeria & Total & Listeria & \\
\hline (a) $0.16 \pm 0.05^{\mathrm{a}} \mathrm{A}$ & (a) $0.14 \pm 0.14^{\mathrm{a}}{ }_{\mathrm{A}}$ & (b) $0.49 \pm 0.09^{\mathrm{a}} \mathrm{A}$ & (b) $0.56 \pm 0.12^{\mathbf{a}}$ A,D & $\begin{array}{c}16.9 \pm 4.3^{\mathbf{a}, \mathbf{d}}{ }_{\mathbf{A}} \\
18.2 \pm 3.5^{\mathbf{a}}{ }_{\mathbf{A}}\end{array}$ \\
\hline (a) $0.02 \pm 0.04^{\mathrm{a}}{ }_{\mathbf{B}}$ & (a) $0.00 \pm 0.11^{\mathrm{a}} \mathrm{A}$ & (a) $0.01 \pm 0.21^{\mathbf{a}}{ }_{\mathbf{B}}$ & (a) $0.22 \pm 0.18^{\mathbf{A}}$ B & $\begin{array}{c}28.6 \pm 1.9^{\mathbf{b}}{ }_{\mathbf{B}} \\
52.8 \pm 15.3^{\mathbf{b}}{ }_{\mathbf{A}}\end{array}$ \\
\hline \multirow[t]{7}{*}{ (a) $0.05 \pm 0.01^{\mathrm{a}}{ }_{\mathrm{B}}$} & (a) $0.05 \pm 0.04^{\mathrm{a}}{ }_{\mathrm{A}}$ & (a) $0.01 \pm 0.02^{\mathrm{a}}{ }_{\text {B }}$ & (b) $0.18 \pm 0.01_{\mathbf{B}}^{\mathbf{b}}$ & $\begin{array}{c}47.7 \pm 2.7^{\mathbf{C}}{ }_{\mathbf{B}} \\
89.2 \pm 18.9^{\mathbf{C}} \\
\end{array}$ \\
\hline & & $0.48 \pm 0.10^{\mathbf{a}}{ }_{\mathrm{A}}$ & $0.50 \pm 0.06^{\mathbf{a}}{ }_{\mathrm{A}}$ & $\begin{array}{c}16.3 \pm 2.1^{\mathbf{a}, \mathbf{d}}{ }_{\mathbf{A}} \\
17.2 \pm 4.0^{\mathbf{a}}{ }_{\mathbf{A}}\end{array}$ \\
\hline & & $0.69 \pm 0.03^{\mathrm{a}} \mathrm{A}, \mathrm{C}$ & $0.40 \pm 0.17^{\mathbf{b}} \mathbf{A , \mathbf { B }}$ & $\begin{array}{l}21.8 \pm 7.3^{\mathbf{d}}{ }_{\mathbf{A}} \\
11.7 \pm 0.6^{\mathbf{a}}{ }_{\mathbf{A}}\end{array}$ \\
\hline & & $0.50 \pm 0.04^{\mathbf{a}}{ }_{\mathbf{A}}$ & $0.55 \pm 0.00^{\mathbf{a}}{ }_{\mathbf{A}, \mathbf{D}}$ & $\begin{array}{c}14.6 \pm 0.1^{\mathbf{a}, \mathbf{e}}{ }_{\mathbf{A}} \\
16.1 \pm 1.2^{\mathbf{a}}{ }_{\mathbf{A}}\end{array}$ \\
\hline & & $0.91 \pm 0.23^{\mathrm{a}} \mathrm{C}$ & $0.94 \pm 0.20^{\mathrm{A}} \mathbf{C}$ & $\begin{array}{l}8.8 \pm 1.7^{\mathbf{e}}{ }_{\mathbf{A}} \\
9.1 \pm 2.0^{\mathbf{a}}{ }_{\mathbf{A}}\end{array}$ \\
\hline & & $0.57 \pm 0.20^{\mathbf{a}} \mathbf{A}$ & $0.60 \pm 0.13^{\mathbf{a}}$ A,D & $\begin{array}{c}13.9 \pm 3.3^{\mathbf{a , e}}{ }_{\mathbf{A}} \\
15.1 \pm 4.7^{\mathbf{a}}{ }_{\mathbf{A}}\end{array}$ \\
\hline & & $0.77 \pm 0.25^{\mathbf{a}}{ }_{\mathbf{C , D}}$ & $0.77 \pm 0.25^{\mathbf{A}}{ }_{\mathbf{C}, \mathbf{D}}$ & $\begin{array}{c}11.1 \pm 3.9^{\mathbf{a , e}}{ }_{\mathbf{A}} \\
15.7 \pm 1.5^{\mathbf{a}}{ }_{\mathbf{A}}\end{array}$ \\
\hline
\end{tabular}

${ }^{+}$Helium flow $(5 \mathrm{~L} / \mathrm{min})$

* Samples were not incubated to allow cell attachment, but treated immediately after cell deposition

${ }^{1}$ Within the same column (4 or 8 min exposure) and the same type of count (Total or Listeria), log-reductions lacking common letters (subscripts) are significantly different (P $\left.\leq 0.05\right)$.

${ }^{2}$ Within the same row (same experiment) and same treatment ( 4 or $8 \mathrm{~min}$ ), log-reductions bearing different superscripts (uppercase letters on the right) are significantly different (P $\leq 0.05$ ).

${ }^{3}$ Exp. I to III: within the same row (same experiment) and same type of count (Total or Listeria), log-reductions bearing different subscripts (brackets on the left) are significantly different (P $\leq 0.05$ ).

${ }^{4}$ For like comparisons (either Listeria or Total), D-values lacking common superscripts are significantly different $(\mathrm{P} \leq 0.05)$.

${ }^{5}$ For comparisons between Listeria and total counts for the same experiment, D-values lacking common subscripts (capital letters) are significantly different (P $\left.\leq 0.05\right)$. 
TABLE 3. Inactivation of Listeria innocua on chicken breast muscle

\begin{tabular}{|c|c|c|c|c|c|c|c|c|c|c|c|c|c|}
\hline \multirow{3}{*}{$\begin{array}{l}\text { Exp. }^{1} \\
I_{(a)}\end{array}$} & \multicolumn{6}{|c|}{ CAP-Pen Treatment Conditions } & \multicolumn{6}{|c|}{$\begin{array}{l}\text { Log-reductions } \\
\left(\log C F U / \mathrm{cm}^{2}\right)\end{array}$} & \multirow{2}{*}{$\begin{array}{c}\text { D-values } \\
\quad(\min )\end{array}$} \\
\hline & $\begin{array}{l}\text { Gap } \\
(\mathrm{cm})\end{array}$ & $\begin{array}{l}\text { Vol. } \\
(\mathrm{kV})\end{array}$ & $\begin{array}{l}\text { Freq. } \\
(\mathrm{kHz})\end{array}$ & $\begin{array}{c}\mathbf{H e} \\
\left(\mathrm{L} \mathrm{min}^{-1}\right)\end{array}$ & $\begin{array}{c}\mathbf{O}_{2} \\
\left(\mathrm{~mL} \min ^{-1}\right)\end{array}$ & Inoculum & $10 \mathrm{~s}$ & $30 \mathrm{~s}$ & $1 \mathrm{~min}$ & $2 \mathrm{~min}$ & $4 \mathrm{~min}$ & $8 \mathrm{~min}$ & \\
\hline & 1.0 & 8.0 & 38.5 & 5.0 & 0.0 & Aliquot & -- & -- & -- & -- & -- & $0.06 \pm 0.04_{A}$ & $162.2 \pm 95.8^{\mathbf{a}}$ \\
\hline $\mathbf{I I}_{(\mathbf{b})}$ & 1.0 & 11.0 & 30.0 & 5.0 & 25.0 & Aliquot & -- & -- & -- & -- & -- & $0.41 \pm 0.02_{\mathbf{B}}$ & $19.5 \pm 0.8^{\mathbf{b}}$ \\
\hline III $_{(\mathbf{a})}$ & 1.0 & 16.0 & 30.0 & 5.0 & 100.0 & Filter & $1.25 \pm 0.26^{\mathrm{a}}$ & $1.58 \pm 0.34^{\mathrm{a}}$ & $1.61 \pm 0.03^{\mathbf{a}, \mathbf{b}}$ & $2.17 \pm 0.56^{\mathbf{b , c}}$ & $2.71 \pm 0.54^{\mathrm{c}}$ & $3.30 \pm 0.14^{\mathbf{d}}$ & $\begin{array}{r}0.1 \pm 0.0^{\mathbf{b}} \\
* 3.4 \pm 0.3^{\mathbf{b}}\end{array}$ \\
\hline
\end{tabular}

\footnotetext{
Initial viable counts of experiments lacking common letters are significantly different $(\mathrm{P} \leq 0.05)$.

${ }^{2}$ Within the same row, log-reductions bearing different superscripts are significantly different $(\mathrm{P} \leq 0.05)$.

${ }^{3}$ Within the same column, log-reductions bearing different subscripts are significantly different $(\mathrm{P} \leq 0.05)$.

${ }^{4} \mathrm{D}$-values bearing different superscripts are significantly different $(\mathrm{P} \leq 0.05)$

*D-values of the second phase (dual-slope survival curves)
} 
A)

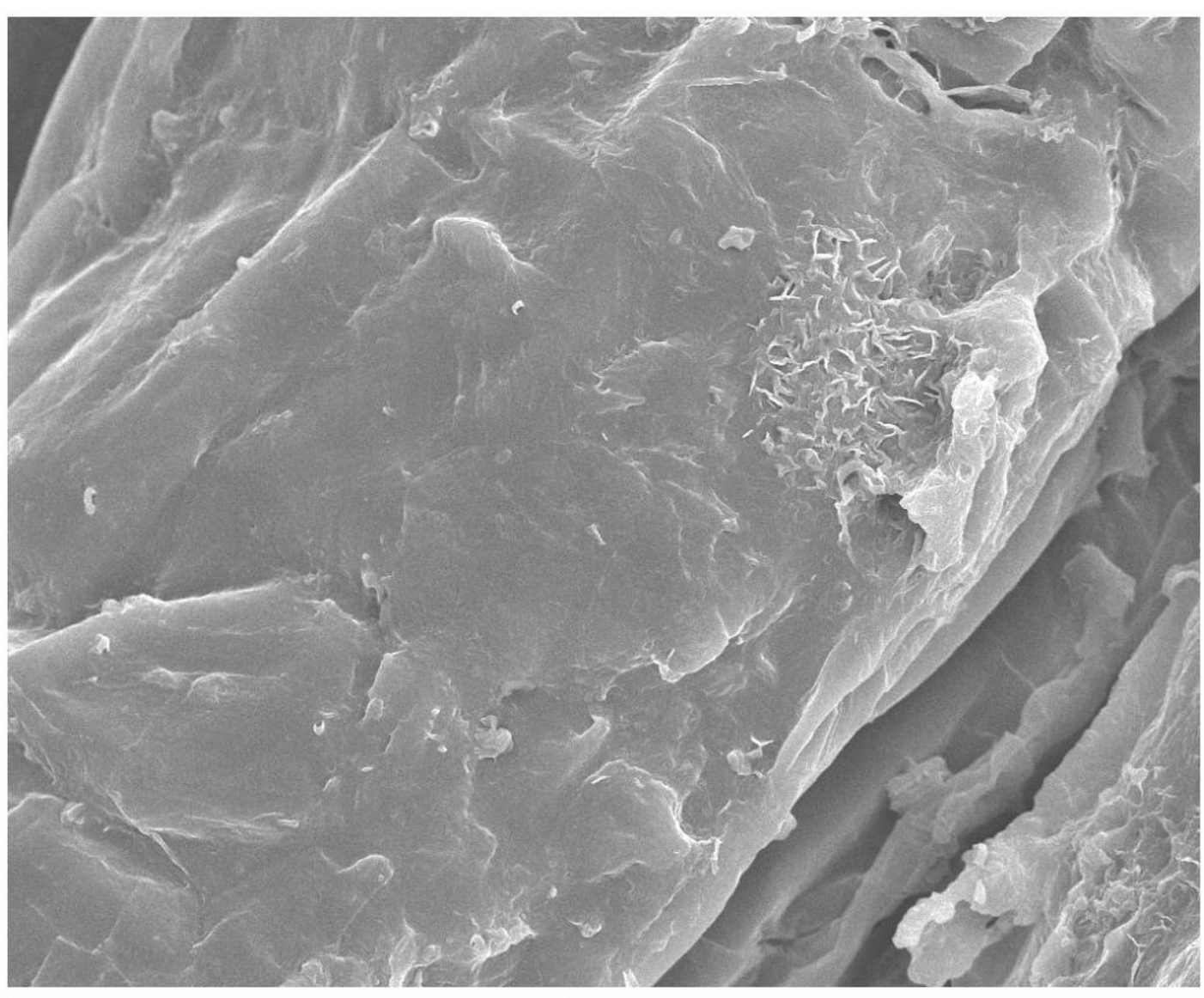

$50 \mu \mathrm{m}$

B)

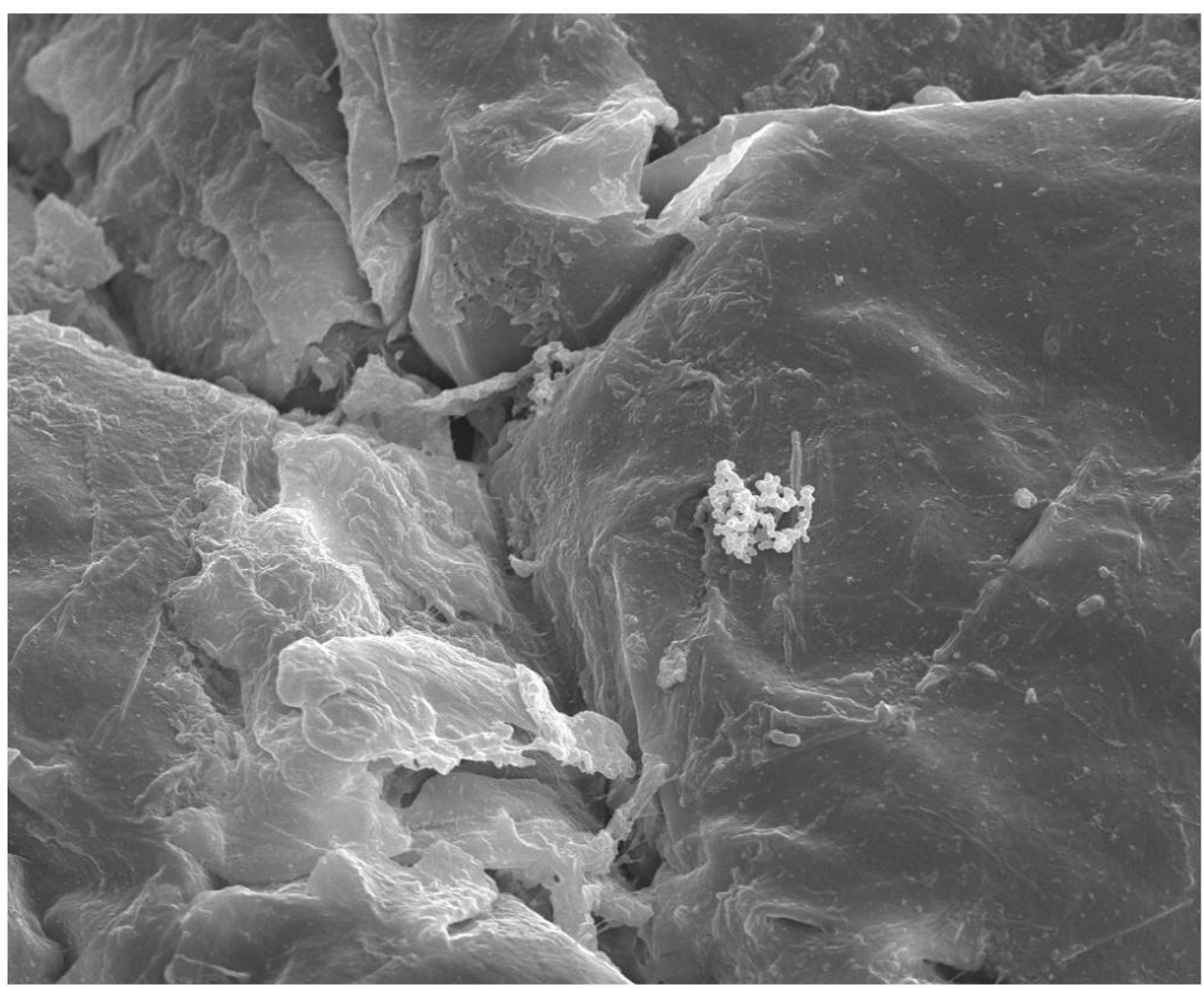


FIGURE 4

A)

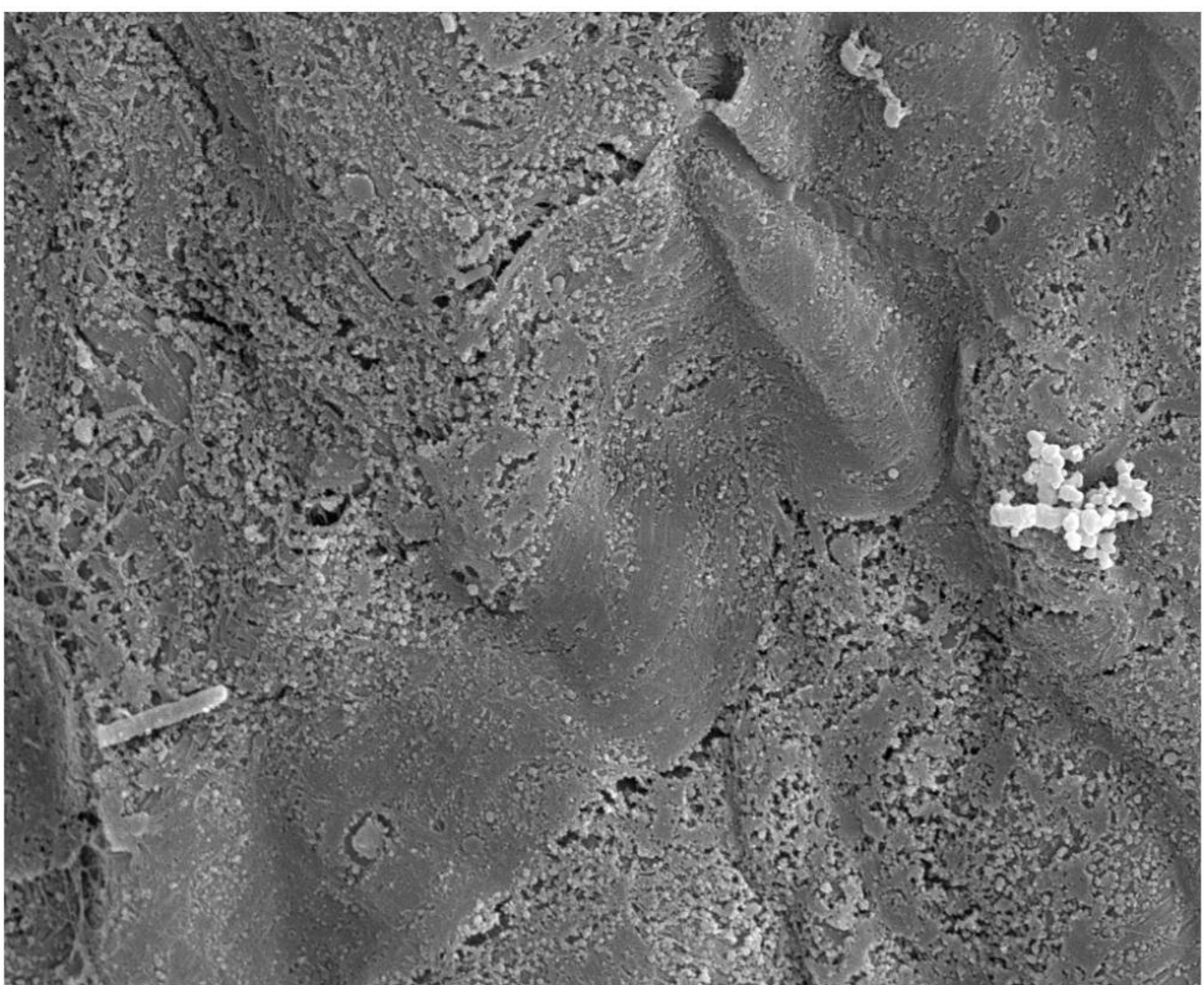

$20 \mu \mathrm{m}$

B)

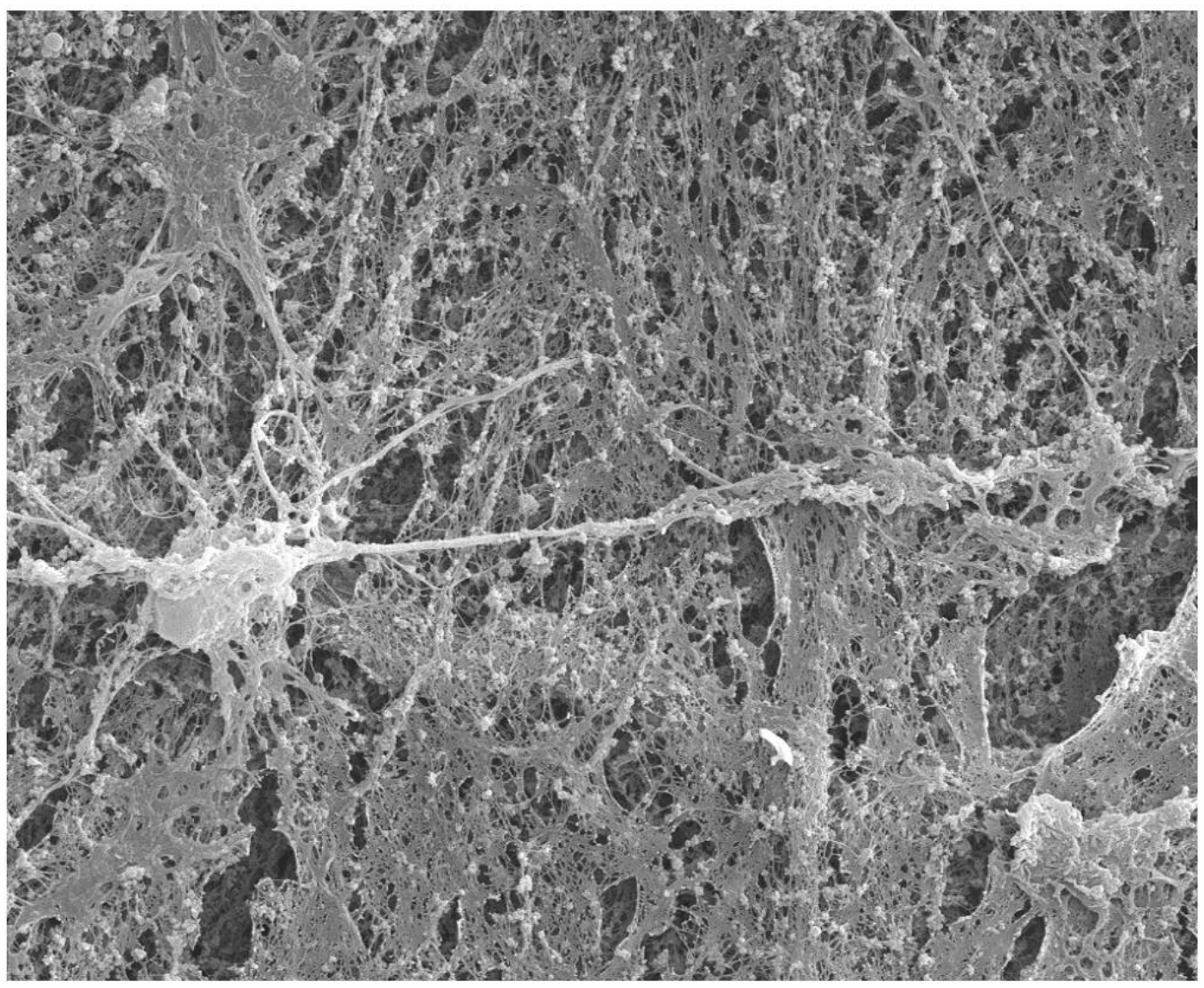

$20 \mu \mathrm{m}$ 
FIGURE 4

C)

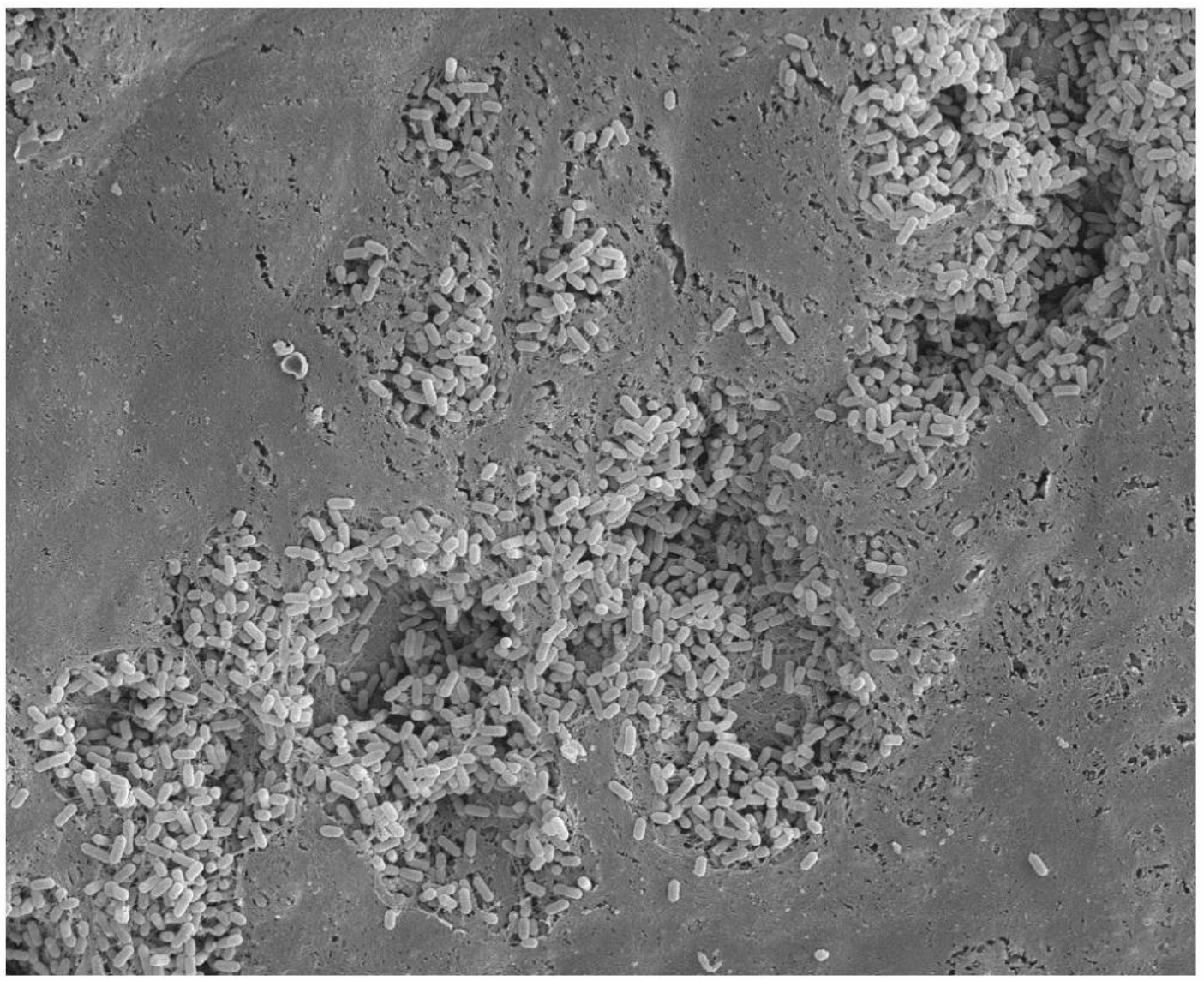

$20 \mu \mathrm{m}$

D)

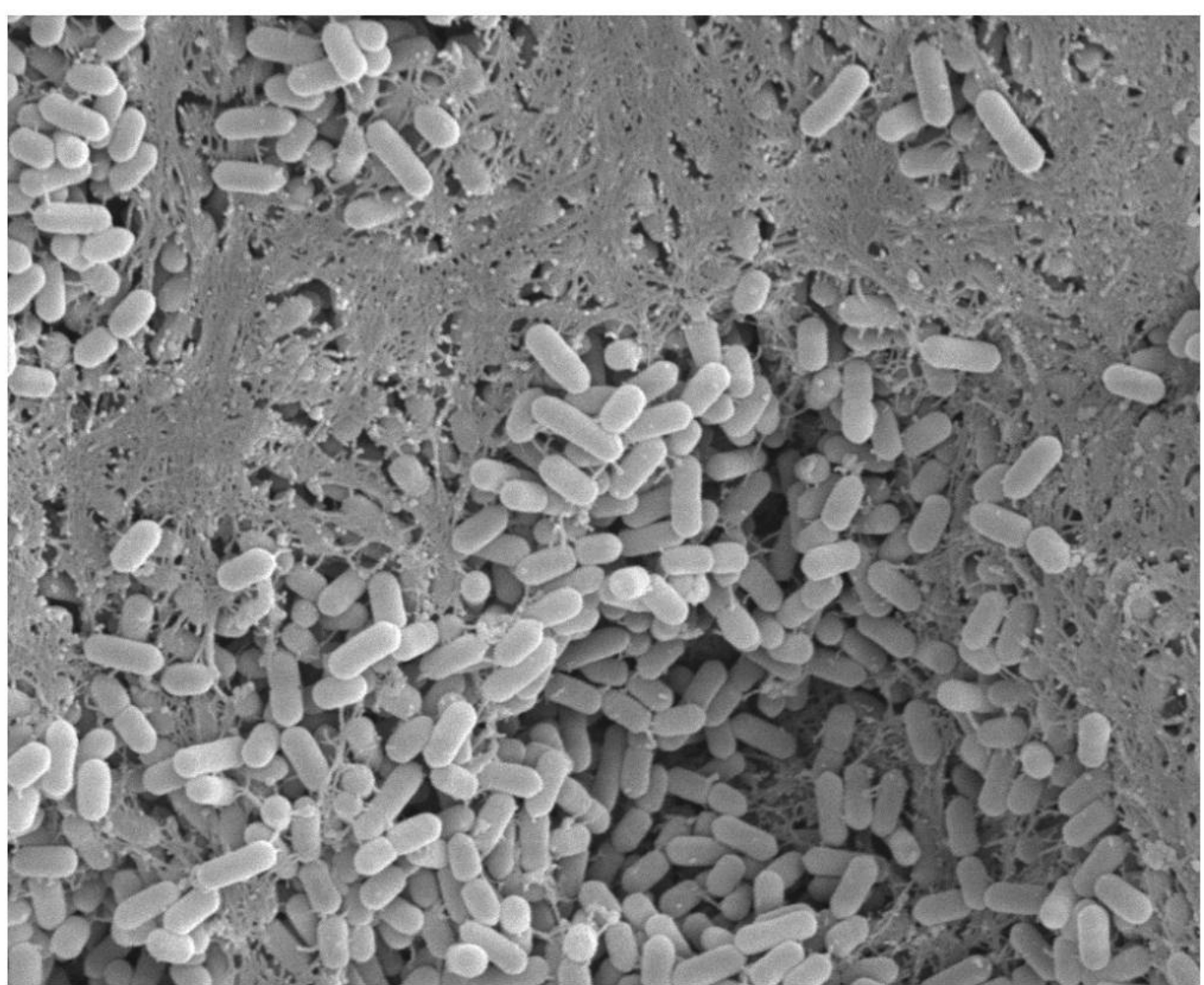

